\title{
Hormônios e micropolíticas de gênero na era farmacopornográfica"
}

\author{
Wagner Xavier de Camargo** \\ Carmen Silvia de Moraes Rial ${ }^{* * * *}$
}

Assalto à razão e delírio artístico, dois ingredientes que fazem de Testo Yonqui uma obra acadêmica à parte, de difícil classificação: Ensaio literário? Etnografia do/no corpo? Manual alternativo de sexualidade? Auto-ajuda para transgêneros mudarem seus corpos com o auxílio de drogas e hormônios? Talvez se possa ler o pujante escrito da (pós)feminista Beatriz Preciado como pós-moderno, com riscos de evocar conceito tão polêmico. Muito provavelmente, porém, ela se irritaria demasiado com a pecha da definição!

Definitivamente, $\mathrm{BP}$ - como se autodenomina na obra - não gosta de definições e classificações. Seu texto talvez seja uma etnografia antropológico-reflexiva, auto-ficção, ou "auto-teoria", como prefere a autora, que usa o próprio corpo como plataforma de análise e experimentação subjetiva. $\mathrm{O}$ que fica dúbio para os

\footnotetext{
* Resenha de PRECIADO, Beatriz. Testo Yonqui. Madrid, Editora Espasa Calpe, 2008, 324p. Recebida para publicação em dezembro de 2009, aceita em maio de 2010. Esta resenha é produto do incentivo da profa. Dra. Miriam Pillar Grossi, a quem devemos gratidão pela apresentação do livro em questão e pelos comentários pertinentes em relação à compreensão da teoria da autora.

** Doutorando em Ciências Humanas na Universidade Federal de Santa Catarina (UFSC), em estágio sanduíche no Instituto Latinoamericano da "Freie Univesität von Berlin", Alemanha. Bolsista CAPES.

wxcamargo@gmail.com

*** Doutora e professora dos departamentos de Antropologia e Interdisciplinar em Ciências Humanas da Universidade Federal de Santa Catarina (UFSC). Pesquisadora CNPq. carmensilviarial@gmail.com
} 
Hormônios e micropolíticas de gênero

leitores é saber onde começam $e$ onde terminam a vida $e$ a arte, $e$ talvez essa seja a contribuição mais interessante de Preciado.

Rizomático ${ }^{1}$, seu livro divide-se em 13 capítulos, que podem ser lidos em qualquer ordem, não havendo uma cronologia ou interdependência entre eles. Não há fio condutor. Curiosamente os capítulos pares são teórico-conceituais e os ímpares registram relatos de experiências, histórias pessoais, encontros $e$ desencontros da própria protagonista-autora-artista. Produto de uma nova estética literária nas produções bibliográficas dos estudos de gênero - ou para sermos mais precisos, nos estudos gays, lésbicos, queer e transexuais - o trabalho de Beatriz Preciado mescla ficção, narrativa, filosofia e arte. Os relatos autobiográficos que emergem (relações sexuais, aplicação de hormônios, humor sarcástico e inúmeras rotas de fuga sem saída), nos entreatos analíticos que a autora apresenta, não são mais do que recursos que exercitam nossas subjetividades contemporâneas e mostram como construí-las ou descontruí-las.

A ideia de Preciado é abrir, a partir de sua etnografia reflexiva, uma discussão mais profunda sobre nossos sexos, nossos desejos, nossas percepções da realidade, acerca de um regime que nos comanda e governa nossas atitudes (ou não-atitudes), em respeito a uma múltipla combinação de fatores. De uma antropologia do corpo a uma filosofia da existência, a autora confere-nos um texto instigante e inovador. O que é questionável, para Preciado, é até que ponto a gestão biomidiática da subjetividade atual está sob controle do indivíduo ou passa

1 Conceito de Gilles Deleuze e Feliz Guattari (2009), o rizoma "conecta um ponto qualquer com outro ponto qualquer e cada um de seus traços não remete necessariamente a traços da mesma natureza (...). Põe em jogo regime de signos muito diferentes e não conduz ao uno, nem ao múltiplo (...). Não se compõe de unidades, mas de dimensões (ou direções movediças); não tem início, nem fim, mas sempre transborda; é feito somente de linhas: de segmentaridade, de estratificação, como dimensões, mas também linhas de fuga ou de desterritorialização, como dimensão máxima segundo a qual, em seguindo-a, a multiplicidade se metamorfoseia, mudando de natureza (Deleuze e Guattari, 2009:32 e ss). 
despercebida por ele: a sua adição consciente à testosterona é parte de um projeto de micromutação fisiológica, política $e$ teórica. $^{2}$

A auto-etnografia propõe-se a ler criticamente a realidade da sociedade contemporânea sob uma perspectiva sexopolítica, onde o sexo e a sexualidade convertem-se no centro da política $e$ da economia. $\mathrm{O}$ que era, até então, considerado por alguns como uma "sociedade do controle", para ela passa a se designar sociedade farmacopornográfica, na qual o controle emerge de dentro do próprio indivíduo. Nessa nova ecologia política não teríamos mais o controle frio, calculado, disciplinar e arquitetônico do panóptico de Jeremy Bentham, explicitado por Michel Foucault ${ }^{3}$, mas sim um "controle pop" implantado no próprio sujeito através de uma plataforma viva de órgãos, fluxos, neurotransmissores e formas de agenciamento, que seriam, ao mesmo tempo, suporte e partes de um programa político novamente aqui encontramos influência deleuziana.

O regime farmacopornográfico, por sua vez, alimenta-se de dois pólos auto-sustentados, que funcionam mais em convergência do que em oposição: a farmacologia (tanto legal quanto ilegal) de um lado, e a pornografia, de outro. A produção farmacopornográfica não é um novo período da economia política mundial pelo volume com que se auto-produz ou pela presença massiva na vida das pessoas, mas pelo seu teor narcoticosexual.

Aqui cabe uma digressão: para Beatriz Preciado, o novo regime farmacopornográfico se anuncia na sociedade científica $e$ colonial do século XIX a partir do duplo movimento de vigilância médico-jurídica em relação às práticas condenadas (aborto, pedofilia e afins) e da espetacularização midiática (de aberrações e anomalias genéticas). Ele tem suas bases hegemônicas constituídas no nascimento da modernidade capitalista, a partir

${ }^{2}$ É clara a influência de Deleuze e Guattari (2009) nos escritos de Preciado: ela faz o que os autores chamam de "micropolítica" no campo social.

${ }^{3}$ Referência a "O Panoptismo" (Foucault, 1991, cap. 3, $3^{\mathrm{a}}$ parte). 
Hormônios e micropolíticas de gênero

das ruínas do sistema feudal. A constituição dos Estados nacionais europeus e a edificação dos regimes de saber científico-técnicos ocidentais estão nas origens da era farmacopornográfica. Contudo, sua efetivação é mais recente: data de fins da Segunda Guerra Mundial, no âmbito da corrida tecnológica espacial, e adquirirá seu atual perfil no desmantelamento da economia fordista dos anos 1970. Pós-industrial, terá um up grade a partir das técnicas informáticas e digitais de visão e difusão de informações.

Nesse contexto, o corpo farmacopornográfico do século XXI não é dócil. É, na verdade, uma interface tecnoorgânica, segmentada e habitada por distintos modelos políticos. Preciado aponta, assim, para um novo tipo de "governabilidade do ser vivo" e submete seu arcabouço feminista (e as próprias teorias feministas) ao solavanco que a aplicação de testosterona provocará em seu corpo durante 236 dias de auto-administração por adesivos cutâneos: há que se saber até que ponto as mutações que se passam nela não são transformações de uma época. ${ }^{4}$

Para a autora, o corpo polissexual vivo é o substrato da força orgásmica. Ele não é produto de um corpo pré-discursivo, como diria Judith Butler (2003), e nem teria seus limites contidos no envoltório da pele. O corpo não pode ser entendido hoje fora dos ditames da tecnociência e, portanto, essa entidade é entrecortada por milhares de fibras óticas, pixels e nanômetros. Trata-se, em realidade, de um tecnocorpo. Convocará Donna Haraway e a definição de tecnobiopoder para explicar porque essa nova tecnoecologia suplanta o biopoder de Foucault, justamente por exercer poder e controle de todo organismo tecnovivo interconectado. ${ }^{5} \mathrm{O}$ que na leitura foucaultiana é biopoder, para Haraway é tecnopoder. E Preciado concorda.

4 Aqui cabe destacar os capítulos mais personalistas acerca da administração hormonal: "Tu Muerte" (cap. 1:19-24) e "Testogel" (cap. 3:47-56).

5 Donna Haraway traz a discussão sobre a figura do "cyborg", ou seja, do ser que descende das implosões de sujeitos e objetos, do natural e do artificial (Haraway, 1991). 
Assim, tanto a biopolítica (poder de controle e produção da vida) como a tanatopolítica (política de controle e gestão da morte) funcionam como farmacopornopolíticas, gestões planetárias de potentia gaudendi ou força orgásmica, potência (real ou virtual) de excitação total de um corpo.

Dessa forma, não só o sexo e a sexualidade poderiam ser pensados de modos diferentes, mas também o gênero. Por isso critica as primeiras teóricas do gênero (Margaret Mead, Mary Macintosh e Ann Oakley) por defini-lo na linha explicativa da "construção social e cultural da diferença sexual" (82). Isso gerou catastróficos efeitos que, em sua opinião, reverberam nas políticas atuais de gênero, de caráter estatal, empurrando o feminino para o beco binomial sem saída essencialismo/ construtivismo. Destaca que Teresa De Lauretis, Judith Butler e Denise Riley vão redesenhar os discursos feministas nos anos 1980.

Para ela, o gênero não nasceu da crítica feminista, mas foi gestado nos laboratórios de farmacopornismo da corrida tecnológica da Guerra Fria, ainda nos anos 40. Hoje não há como discutir o gênero. Há que se discutir as "tecnologias de gênero" (termos de Haraway), que codificam, descodificam, programam e desprogramam e são sintéticas, maleáveis, suscetíveis de serem transferidas, copiadas, produzidas e reproduzidas tecnicamente pelos sexos e gêneros dos "bio" e "tecno" sujeitos. ${ }^{6}$

É esse novo sujeito sexual farmacopornográfico que mantém e alimenta o farmacopoder. Lembrando o mecanismo disciplinar de controle do panóptico, seria como se agora esse

${ }^{6}$ Surgem as nomenclaturas bio $e$ trans, como estatutos de gênero tecnicamente produzidos. Por um lado, os bio-homens $e$ as bio-mulheres são aqueles que se identificaram com o sexo que lhes foi designado no nascimento $e$, por outro, os trans-homens $e$ as trans-mulheres são os que contestaram tal designação $e$ tentaram modificá-la com ajuda de procedimentos externos (técnicos, prostéticos, performativos e/ou legais). Tais designações não são melhores ou piores umas em relação às outras. Apenas dão conta do abismo que separa as pessoas bio das pessoas trans. Tal distinção, para a autora, tornar-se-á ultrapassada no futuro (Preciado, 2008:84 e ss). 
Hormônios e micropolíticas de gênero

fosse comestível e estivesse operando de dentro do sujeito e por ele próprio. Como exemplo, a autora lembra o caso das pílulas anticoncepcionais, inventadas e maciçamente divulgadas no meio do século XX com o que considera ser a fachada de controle de natalidade. A pílula feminina sempre funcionou, desde sua descoberta, não como uma técnica de controle da reprodução, mas de produção e controle de gênero, de acordo com Preciado. E mais: como foi elaborada para reproduzir tecnicamente os ritmos dos ciclos menstruais - ou seja, "imitar tecnicamente a natureza" - a autora sugere uma analogia: assim como as "drag queens" são homens biológicos que desempenham uma forma visível de feminilidade e as "drag kings" são mulheres biológicas que teatralizam uma forma de masculinidade, a pílula seria uma "bio-drag", uma espécie de travestismo somático, ou ainda, "produção farmacopornográfica de ficções somáticas de feminilidade e de masculinidade" (130). O que se produz não é algo externo (estilo, vestimenta, comportamento social), mas um processo biológico.

A fonte última de produção e riqueza do regime econômico pós-industrial farmacopornográfico é a pornografia que se prolifera pelos suportes técnicos (TV, computador, etc.) em ondas óticas para todo o planisfério terrestre. É ela que, no limite, alimenta o pornopoder. Como dispositivo virtual (literário, audiovisual, cibernético) masturbatório, a pornografia é a sexualidade transformada em espetáculo. Nesse sentido, para a autora, ela estaria para a indústria cultural, assim como a indústria do tráfico de drogas estaria em estreita relação com a indústria farmacêutica. Na pornografia, o sexo é performance, isto é, uma representação pública e um processo de repetição continuada, politicamente regulada. Nem o corpo individual, nem a esfera privada e nem o espaço doméstico escapariam da regulação política. Dessa forma presenciamos, então, um processo de "pornificação do trabalho", pois na economia farmacopornista, o trabalho é sexo. Como o termo "sexual" (no antigo conceito de divisão sexual do trabalho) silencia o aspecto normativamente 
heterossexual da reprodução, conferindo-lhe um caráter de única via natural, Preciado propõe reclassificar o conceito para "divisão gestacional do trabalho", devido à ênfase na segmentação do corpo derivada da capacidade (ou não) de gestação em útero.

Contudo, destaca que presenciamos no regime farmacopornográfico um processo dialético entre fármaco $e$ porno. Tal dialética estaria manifesta através de contradições de biocódigos (low tech ou high tech), que formam a subjetividade $e$ que procedem de regimes diferentes de produção do corpo. Dessa maneira, assistiríamos a uma horizontalização das técnicas de produção do corpo, que não estabelece diferenças entre classes sociais, raça ou sexualidade, ou outras características. A partir dessa horizontalização que, de acordo com $\mathrm{BP}$, se depreenderia que a heterossexualidade será tão somente uma estética farmacopornográfica como qualquer outra (ou muitas), que poderá ser imitada, exportada e apreciada, mas que já se apresentaria como modelo falido e decadente em nossas sociedades contemporâneas. Para ela, a heterossexualidade está fadada a desaparecer e em seu lugar haverá uma proliferação de produção de corpos e de prazeres desviantes, outrossim, igualmente submetidos às regulações farmacopornográficas.

$\mathrm{Da}$ radicalidade de Preciado em momentos de autoexperimentação, passando pelas densas argumentações teóricas e quedas livres que nos arremessam ao precipício, se não fossem ficções "somato-políticas", como a própria autora destaca, elas provocariam em seus leitores insurreição contra uma ativista tão respeitada pelos estudos feministas. No entanto, Preciado não engana a quem está atento: apesar do tom catastrofista e do anúncio da auto-extinção imanente do ser humano, deixa possíveis saídas em seus capítulos finais ${ }^{7}$ : aplicações maciças de testosterona e oficinas performáticas de drag king para bio-

7 Mais precisamente em "Micropolíticas de Gênero en la Era Farmacopornográfica. Experimentación, intoxicación voluntaria, mutación” (cap. 12:233-286). 
Hormônios e micropolíticas de gênero

mulheres figurariam como propostas do que chama "micropolíticas de resistência" de gênero - aqui, novamente, a referência são as "micropolíticas do campo social" (Deleuze e Guattari, 2009:15).

Preciado anda às voltas com amigos e amigas em sua obra, sempre misturando propositalmente os gêneros e denominando-os por siglas (VD, V, GD). O protocolo de "intoxicação voluntária" que executa por rituais de administração de hormônio masculino, não significa mudança de sexo ou uma metamorfose transexual. É um processo de desnaturalização e de desidentificação. Mudam-se apenas os afetos e seu corpo.

O corpo é uma condição de perfeição e de ruína. Para ela, os corpos são recipientes inexoráveis de transporte de substâncias ilícitas e produtores de subjetividades adictas. São receptáculos produtores de excitação-frustração e circuito sob controle da gestão farmacopornográfica. O que importa, segundo ela, não é a produção de prazer, mas o controle do mecanismo cíclico excitação-frustração-excitação e de sua infinita repetição, que é justamente o motor do farmacopornismo em escala global. Está em cena, então, uma cooperação masturbatória entre corpos insatisfeitos, insaciáveis - que buscam hormônios, cocaína, pênis, vaginas, ânus - e novas formas de produção da repetição do mecanismo na contemporaneidade.

O legado de Beatriz Preciado com esta obra vai além de uma contribuição estilística e artística personalizada em estilo literário. Pode ser considerado uma nova luz-guia nas discussões acerca dos estudos de gênero e das produções das subjetividades dos (pós)corpos contemporâneos. Merece ser apreciado.

\section{Referências bibliográficas}

BUTLER, Judith. Problemas de Gênero: feminismo e subversão da identidade. Rio de Janeiro, Civilização Brasileira, 2003. 
Deleuze, Gilles e GuATtARI, Félix. Mil Platôs. Capitalismo e Esquizofrenia, vol. 1. 6 $6^{\text {a }}$ ed. São Paulo, Ed. 34, 2009 [Tradução Aurélio Neto e Célia Costa].

FOUCAUlT, Michel. O Panoptismo. In: FOUCAUlT, M. Vigiar e punir: nascimento da prisão. $8^{\mathrm{a}}$ ed. Rio de Janeiro, Vozes, 1991, pp.173199.

HaRAWAY, Donna. A Cyborg Manifesto: Science, Technology, and Socialist-Feminism in the Late Twentieth Century. In: HARAWAY, D. Simians, Cyborgs and Women: The Reinvention of Nature. New York, Routledge, 1991, pp.149-181. 